\title{
STRATEGI PENGEMBANGAN SALAK NGLUMUT BERSERTIFIKAT PRIMA 3 DI KABUPATEN MAGELANG
}

\author{
Suharso $^{1}$, M.A. Legowo ${ }^{2}$ dan A. Setiadi ${ }^{2}$ \\ ${ }^{1}$ Dinas Ketahanan Pangan Propinsi Jawa Tengah \\ ${ }^{2}$ Fakultas Peternakan dan Pertanian, Universitas Diponegoro, Semarang \\ Email :suharso_bkpjateng@yahoo.co.id \\ Diterima 26 Januari 2017, disetujui 6 Maret 2017
}

\begin{abstract}
ABSTRAK
Penelitian ini bertujuan untuk : a) menganalisis faktor-faktor yang mempengaruhi keputusan petani untuk melakukan sertifikasi, b) merumuskan strategi pengembangan Salak Nglumut Bersertifikat Prima 3 di Kabupaten Magelang. Penelitian menggunakan metode survey. Lokasi penelitian di Kecamatan Srumbung yang ditetapkan secara purposive sampling berdasarkan jumlah produksi tertinggi salak. Penelitian dilakukan dari bulan Maret 2015 sampai Juni 2015. Sampel adalah petani Salak Nglumut yang terdiri dari 89 orang petani bersertifikat dan 83 orang petani tidak bersertifikat prima 3 yang ditentukan dengan proporsional random sampling. Penetapan responden untuk analisis strategi pengembangan menggunakan key person sebanyak 30 untuk penggalian informasi melalui FGD (Forum Group Discussion) ditentukan secara purposive.Analisis menggunakan binary logistic dan SWOT. Hasil penelitian menunjukkan bahwa faktor-faktor yang signifikan positif mempengaruhi keputusan petani bersertifikasi prima 3 adalah tingkat pendidikan dan pendapatan petani, sedangkan variabel umur dan luas lahan tidak menunjukkan pengaruh yang signifikan. Strategi pengembangan Salak Nglumut adalah strategi yang mendukung pertumbuhan agresif dengan memanfaatkan peluang (S-O), meliputi : a) Teknologi budidaya dan manajemen usaha diarahkan menggunakan pedoman budidaya yang baik (Good Agricultural Practice) menuju sertifikasi produk prima; b) Penerapan standarisasi produk (penyeragaman mutu dan ukuran salak); c) Penguatan pengembagan pasar, membuka jaringan pemasaran dan orientasi ekspor dan d) Pengembangan usaha dan peningkatan kapasitas produksi.
\end{abstract}

Kata Kunci :keputusan, sertfikat prima 3, salak nglumut, logit, SWOT

\begin{abstract}
The aims of this study were to: a) analyze the factors that influence the farmers' decision certifications, b) to formulate development strategy Salak Nglumut Certified Prima 3 in Magelang. The study used a survey method. The research location Srumbung defined by purposive sampling based on the highest production amount bark. The study was conducted from March 2015 to June 2015. The samples were farmers Salak Nglumut consisting of 89 farmers certified and 83 farmers not certified prime 3 determined by proportional random sampling. Determination of the respondents to the analysis of development strategies using key persons as much as 30 for extracting information through FGD (Focus Group Discussion) purposively. Analisis determined using binary logistic and SWOT. The results showed that the
\end{abstract}


significant factors that positively influence the farmer's decision-certified prime 3 were the level of education and income of farmers, while the variable age and land area did not show a significant effect. The development strategy Salak Nglumut were supported the aggressive growth strategies by utilizing opportunities (SO), include : a) cultivation technology and business management directed to use the guidelines good farming (Good Agricultural Practice) towards the certification of product excellence; b) Application of product standardization (uniformity the quality and size of the bark); c) Strengthening developing a market, open up marketing network and export orientation and d) development of business and increase production capacity.

Keywords: decision, prima cert 3, barking Nglumut, logit, SWOT

\section{PENDAHULUAN}

Salak nglumut merupakan komoditas unggulan serta andalan di Kabupaten Magelang. Jenis buah ini merupakan buah asli Indonesia yang memiliki prospek cukup baik untuk dikembangkan sebagai komoditi ekspor. Keunggulan Salak Nglumut terletak pada rasa yang khas dimana tidak dimiliki oleh jenis salak lainnya yaitu rasa daging buah salak yang manis meskipun umurnya masih muda.

Tantangan yang dihadapi untuk pengembangan komoditas Salak Nglumut adalah meningkatkan kualitas, kuantitas dan kontinuitas produksi. Saat ini konsumen telah menyadari arti penting mutu buah dan keamanan pangan, oleh karena itu untuk menghasilkan komoditas yang dapat diterima pasar secara luas petani harus memperhatikan dan mengikuti kaidah-kaidah dan prosedur pelaksanaan untuk menghasilkan produk yang berkualitas.

Upaya menghasilkan salak yang berkualitas, dibutuhkan suatu perencanaan proses produksi yang menjamin diperolehnya buah sesuai dengan standard mutu yang ditetapkan. Proses produksi tersebut meliputi suatu serangkaian norma produksi yang baik atau sering disebut dengan GAP (Good Agricultural Practice) atau SPO (Standar Prosedur Operational) salak. Dasar hukum penerapan GAP/SPO di Indonesia adalah Peraturan Menteri Pertanian Nomor : 61/Permentan/OT.160/11/2006, tanggal 28 November 2006 untuk komoditi buah. Ruang Lingkup Pedoman Budidaya Buah yang Baik meliputi (1). Lahan, (2). Penggunaan Benih dan Varietas Tanaman, (3). Penamaan, (4). Pemupukan, (5). Perlindungan Tanaman,(6). Pengairan, (7). Pengelolaan/Pemeliharaan Tanaman, (8). Panen, (9). Penanganan Pasca Panen, (10). Alat dan Mesin Pertanian, (11). Pelestarian Lingkungan, (12). Tenaga Kerja, (13). Fasilitas Kebersihan, (14). Tempat Pembuangan 15. Pengawasan Pencatatan dan Penelusuran Balik (16). Sertifikasi, (17). Pembinaan

Dalam rangka mendorong pertumbuhan dari pengembangan usaha agribisnis buahbuahan perlu suatu acuan dalam proses produksi dan penanganan pascapanen buahbuahan, salah satunya adalah sertifikasi. Sertifikasi dilaksanakan oleh lembaga yang mempunyai kewenangan malaksanakan penilaian terhadap proses produksi usaha budidaya tanaman buah. Produk bersertifikat menunjukkan bahwa produk tersebut telah mengacu pada Pedoman Budidaya Buah yang Baik/GAP, dan telah menerapkan tahapantahapan yang tertuang dalam Standard Prosedur Operasi (SPO) dari masing-masing komoditas buah. Permintaan pasar yang semakin tinggi atas pangan yang sehat dan aman, belum sepenuhnya terpenuhi karena terbatasnya petani yang menerapkan budidaya pertanian yang sesuai GAP/SOP (Dinas PPertanian Tanaman Pangan dan Hortikultura. 2013).

Usahatani Salak Nglumut di Kabupaten Magelang mempunyai nilai penting dalam meningkatkan kesejahteraan penduduk. Pengembangan agribisnis salak ini sangat prospektif, untuk menjangkau pasar yang lebih luas menuju pasar ekspor, maka 
sertifikasi sudah menjadi keharusan. Upaya peningkatan produksi dan mutu buah bermutu dalam jumlah yang mencukupi dan aman dikonsumsi maka diperlukan tahapan budidaya yang benar dan sertifikasi. Studi yang dilakukan oleh Sugino dan Mayrowani (2010) mengatakan bahwa bagi konsumen asing sertifikat pangan organik adalah penting, sedangkan bagi konsumen domestik sertifikasi itu penting jika tidak mempengaruhi harga. Sertifikat Prima 3 adalah penetapan buah salak sebagai landasan kebijakan untuk buah ekspor. Strategi pengembangan agribisnis salak nglumut bersertifikat Prima 3 yang tepat akan mampu menjaga daya saing dan eksistensi usaha. Penelitian ini bertujuan untuk menganalisis: 1) Faktor-faktor yang mempengaruhi keputusan petani untuk melakukan sertifikasi dan 2) Merumuskan strategi pengembangan agribisnis Salak Nglumut Bersertifikat Prima 3 di Kabupaten Magelang.

\section{METODE PENELITIAN}

Penelitian ini dilaksanakan pada empat desa produksi yang sudah menerapkan Sertifikasi Prima 3. Desa tersebut adalah Kamongan, Kaliurang, Nglumut dan Kradenan, Kecamatan Srumbung, Kabupaten Magelang. Survei dilaksanakan dari Bulan Maret sampai dengan Juni 2015. Responden terdiri atas petani bersertifikat dan tidak bersertifikat ditentukan dengan metode proportional stratified random sampling, masing-masing sebanyak 89 dan 82 orang
(Tabel 1). Teknik pengumpulan data untuk mengetahui alternatif strategi dan prioritas strategi yang layak diterapkan dalam pengembangan agribisnis Salak Nglumut Bersertifikat Prima 3 di Kabupaten Magelang adalah dengan metode wawancara, kuesioner dan Focus Group Discussion(FGD). Focus Group Discussion (FGD) dilakukan melalui brainstorming dan dialog dengan berbagai pihak yang terkait dan dianggap berkompeten terhadap permasalahan dalam pengembangan agribisnis Salak Nglumut di Kabupaten Magelang. Penentuan key person yang dijadikan responden untuk menganalisis perumusan strategi pengembangan Salak Nglumut bersertifikat Prima 3 di Kabupaten Magelang sebanyak 30 orang yang terdiri dari unsur akademisi sebanyak 4 orang, petani salak bersertifikat prima 3 sebanyak 10 orang, pedagang/distributor salak bersertifikat prima 3 sebanyak 4 orang, instansi dinas terkait sebanyak 8 orang, dan masyarakat terkait sebanyak 4 orang).

Analisis faktor-faktor yang mempengaruhi pengambilan keputusan melakukan sertifikasi digunakan model regresi logistic mengacu pada Saefuddin et al. (2009) :

$Y=\ln \left[\frac{p}{1-p}\right]=\beta_{0}+\beta_{1} x_{1}+\beta_{2} x_{2}+\beta_{3} x_{3}+\beta_{4} x_{4}+u$

Keterangan:

$\mathrm{Y}=$ Keputusan petani salak nglumut $(1=$ bersertifikat prima 3 , $0=$ tidak bersertifikat prima 3 )

Tabel 1. Jumlah Populasi Petani Salak

\begin{tabular}{llcccc}
\hline \multirow{2}{*}{ No } & Lokasi Desa & $\begin{array}{c}\text { Petani } \\
\text { Bersertifikat } \\
\text { (orang) }\end{array}$ & $\begin{array}{c}\text { Petani Tidak } \\
\text { Bersertifikat } \\
\text { (orang) }\end{array}$ & $\begin{array}{c}\text { Petani } \\
\text { Bersertifikat } \\
\text { (orang) }\end{array}$ & $\begin{array}{c}\text { Petani Tidak } \\
\text { Bersertifikat } \\
\text { (orang) }\end{array}$ \\
\hline 1 & Kamongan & 141 & 158 & 26 & 28 \\
2 & Kaliurang & 443 & 156 & 50 & 28 \\
3 & Nglumut & 125 & 90 & 14 & 16 \\
4 & Kradenan & 80 & 58 & 9 & 10 \\
& Jumlah & 789 & 462 & 89 & 82 \\
\hline
\end{tabular}

Sumber : Data Kelompok Tani Salak, Kabupaten Magelang, 2014 
$\mathrm{X} 1=$ Umur petani (tahun)

$\mathrm{X} 2$ = Luas lahan budidaya salak (ha)

X3 = Pendidikan petani(tahun)

$\mathrm{X} 4=$ Pendapatan petani(skor)

B0 $=$ Konstanta

ß1-4= Koefisien regresi

$u=$ error term

Analisis strategi pengembangan Salak Nglumut mengunakan SWOT (Strengths, Weaknesses, Opportunities and Threats) (Rangkuti, 2002). Pengembangan usaha Salak Nglumut bersertifikat Prima 3 meliputi analisis lingkungan internal yaitu berupa variabel kekuatan dan kelemahan serta analisis lingkungan eksternal yang berupa variabel peluang dan ancaman.

\section{HASIL DAN PEMBAHASAN}

\section{Karakteristik Responden}

Karakteristik responden meliputi umur, pendidikan, luas lahan seperti ditampilkan pada Tabel 2. Sebagian besar petani (65\%) berada pada kisaran umur 36-55 tahun. Petani pada umur 26-35 tahun sebanyak 29 petani $(16,96 \%)$. Petani responden yang umurnya lebih dari 56 tahun sebanyak 20 petani $(11,70 \%)$. Sedangkan petani responden yang umurnya kurang dari 25 tahun yaitu 9 petani $(5,26 \%)$. Petani responden sebagian besar masih dalam katagori umur produktif. Umur petani akan mempengaruhi kemampuan fisik dan respon terhadap hal-hal baru dalam menjalankan usahataninya. Ada kecenderungan bahwa petani muda lebih cepat mengadopsi suatu inovasi karena mereka

Tabel 2. Distribusi Responden Berdasarkan Umur

\begin{tabular}{lcc}
\hline \multicolumn{1}{c}{ Umur } & Jumlah & Persentase \\
\hline & ---orang -- & $---\%$--- \\
$\leq 25$ tahun & 9 & 5,26 \\
26-35 tahun & 29 & 16,96 \\
36-45 tahun & 49 & 28,65 \\
46-55 tahun & 64 & 37,43 \\
>56 tahun & 20 & 11,70 \\
Jumlah & 171 & 100,00 \\
\hline
\end{tabular}

Sumber : Data primer diolah, 2016 mempunyai semangat untuk mengetahui halhal baru termasuk sertifikasi. Menurut Soekartawi (1988) menyatakan bahwa faktor umur merupakan salah satu faktor yang mempengaruhi dalam pengambilan keputusan, makin muda usia petani, mereka lebih cepat melakukan adopsi inovasi. Mardikanto et al. (1996) menyampaikan bahwa semakin tua (diatas 50 tahun), biasanya semakin lamban mengadopsi inovasi, dan cenderung hanya melaksanakan kegiatan-kegiatan yang sudah biasa diterapkan secara turun temurun atau dilakukan masyarakat setempat.

Pendidikan merupakan proses yang dilalui seseorang dalam rangka meningkatkan pengetahuan, keterampilan dan sikap. Proses peningkatan pengetahuan, keterampilan dan sikap ini bisa ditempuh melalui pendidikan formal dan pendidikan non formal. Tingkat pendidikan seseorang akan mempengaruhi pola pikir seseorang dalam menghadapi sesuatu. Pendidikan petani responden dapat dilihat pada Tabel 3.

Tabel 3. Distribusi Responden Berdasarkan Tingkat Pendidikan Formal

\begin{tabular}{lcr}
\hline \multicolumn{1}{c}{ Kategori } & Jumlah & Persentase \\
\hline Tidak tamat SD & ---orang -- & $---\%---$ \\
SD & 2 & 1,17 \\
SLTP/SMP & 69 & 40,35 \\
SLTA/SMU & 62 & 36,26 \\
PerguruanTinggi & 32 & 18,71 \\
\hline Jumlah & 6 & 3,51 \\
\hline
\end{tabular}

Sumber : Data primer diolah, 2016

Berdasarkan Tabel 3 dapat diketahui bahwa pendidikan formal yang ditempuh petani responden mayoritas yaitu sebanyak 69 petani $(40,35 \%)$ hanya sampai tingkat $\mathrm{SD} /$ sederajat. Petani yang melanjutkan pendidikannya sampai tingkat SLTP/sederajat sebanyak 62 petani $(36,26 \%)$ dan tingkat SLTA/sederajat 32 petani $(18,71 \%)$. Menurut Soekartawi (1988) mereka yang berpendidikan tinggi akan relatif lebih cepat dalam melaksanakan adopsi inovasi.

Luas lahan yang diusahakan oleh petani akan berpengaruh pada produksi pertanian. 
Luas lahan sawah yang dikuasai petani akan sangat menentukan besar pendapatan yang diperoleh dari usahatani. Luas lahan yang diusahakan oleh petani dalam budidaya salak dapat dilihat dari Tabel 4.

Tabel 4. Distribusi Responden Berdasarkan Luas Lahan yang Diusahakan

\begin{tabular}{lcc}
\hline Luas lahan & Jumlah & Persentase \\
\hline & ---orang -- & $---\%---$ \\
$\leq 0,25$ ha & 31 & 18,13 \\
$0,26-0,50$ ha & 65 & 38,01 \\
$0,51-0,75$ ha & 43 & 25,15 \\
$0,76-0,99$ ha & 20 & 11,70 \\
$\geq 1$ ha & 12 & 7,02 \\
\hline Jumlah & 171 & 100,00 \\
\hline
\end{tabular}

Sumber : Data primer diolah, 2016

Berdasarkan Tabel 4 petani responden sebagian besar mengusahakan lahan usahatani dengan luas $0,26-0,50$ ha yaitu sebanyak 65 petani $(38,01 \%)$. Petani yang mengusahakan lahan dengan luas kurang dari 0,51-0,75 ha sebanyak 43 petani $(25,15 \%)$. Petani yang mengusahakan lahan dengan luas kurang dari 0,25 ha sebanyak 31 petani $(18,13 \%)$. Petani dengan luas usaha 0,76-0,99 ha sebanyak 20 petani $(11,70 \%)$. Sedangkan petani yang mengusahakan lahan usahatani dengan luas lebih dari 1 ha masing-masing sebanyak 12 petani $(7,02 \%)$. Luas lahan yang diusahakan oleh petani relatif sempit karena biasanya lahan yang mereka usahakan merupakan warisan orang tua yang dibagi dengan saudaranya. Namun ada juga petani yang membeli sendiri dan ada juga petani yang berhasil memperluas lahan usahatani yang mereka usahakan. Menurut Mardikanto (1996) semakin luas lahan usahatani biasanya semakin cepat mengadopsi, kerena memiliki kemampuan ekonomi yang lebih baik.

Tingkat pendapatan petani responden merupakan tingkat pendapatan yang diperoleh baik dari pertanian maupun non pertanian. Tingkat pendapatan diukur dari kemampuannya untuk memenuhi kebutuhan pokok sehari-hari, pendidikan, kesehatan dan kemampuan untuk menyisihkan uang untuk menabung (Tabel 5).
Tabel 5.Distribusi Responden Berdasarkan Tingkat Pendapatan

\begin{tabular}{lcc}
\hline \multicolumn{1}{c}{ Kategori } & Jumlah & Persentase \\
\hline & ---orang -- & $---\%$--- \\
Sering kekurangan & 2 & 1,17 \\
Kadang kekurangan & 32 & 18,71 \\
Cukup & 82 & 47,95 \\
Kadang bisa menabung & 45 & 26,32 \\
Selalu bisa menabung & 10 & 5,85 \\
\hline Jumlah & 171 & 100,00 \\
\hline
\end{tabular}

Sumber : Data primer diolah, 2016.

Tabel 5 menunjukkan bahwa sebagian besar petani masuk dalam kategori cukup dalam arti petani tidak pernah kekurangan dalam memenuhi kebutuhan hidupnya namun sulit menyisihkan sebagian pendapatannya untuk ditabung yaitu 82 petani (47,95\%). Sebesar $32,17 \%$ petani mempunyai kemampuan untuk menyisihkan uang untuk menabung. Petani memiliki sumber pendapatan dari sektor pertanian dan non pertanian.Selain pendapatan dari usahatani salak, pendapatan keluarga petani juga diperoleh dari berkebun, berternak, berdagang, menjahit, buruh bangunan, dan sebagainya.

\section{Faktor-Faktor yang mempengaruhi Kepu- tusan Petani melakukan Sertifikasi Prima 3}

Pengambilan keputusan merupan bagian dari perencanaan. Setiap keputusan merupakan rencana atau bagian dari rencana.secara umum dapat dikatakan bahwa, pengambil keputusan dalam keluarga petani adalah ayah atau suami yang menjadi kepala keluarga itu (Mardikanto,1996). Hasil analisis regresi logistik pada Tabel 6 didapatkan persamaan:

$Y=20,199+0,224 X_{1}+0,190 X_{2}+4,283$ $\mathrm{X}_{3}+2,671 \mathrm{X}_{4}$

Variabel tingkat pendidikan $\left(\mathrm{X}_{3}\right)$ dan pendapatan petani $\left(\mathrm{X}_{4}\right)$ secara statistik berpengaruh positif secara signifikan mempengaruhi keputusan untuk bersetifikat Prima 3 yang ditunjukkan dari nilai signifikansi sebesar 0,000. Sedangkan variabel umur $\left(\mathrm{X}_{1}\right)$ dan luas lahan $\left(\mathrm{X}_{2}\right)$ tidak 
Tabel 6. Hasil Analisis Regresi Logistik

\begin{tabular}{lrrrrr}
\hline \multicolumn{1}{c}{ Variabel } & \multicolumn{1}{c}{ B } & \multicolumn{1}{c}{ SE } & \multicolumn{1}{c}{ Wald } & \multicolumn{1}{c}{ Sig. } & \multicolumn{1}{c}{$\operatorname{Exp}(\mathrm{B})$} \\
\hline Konstanta & -20.199 & 3.956 & 26.07 & $0.000^{*}$ & 0.000 \\
Umur & 0.224 & 0.416 & 0.291 & $0.589^{\text {ns }}$ & 1.251 \\
Lahan & 0.19 & 0.324 & 0.343 & $0.558^{\text {ns }}$ & 1.209 \\
Pendidikan & 4.283 & 0.707 & 36.657 & $0.000^{*}$ & 72.439 \\
Pendapatan & 2.671 & 0.716 & 13.927 & $0.000^{*}$ & 14.455 \\
\hline
\end{tabular}

Keterangan : $\left.{ }^{*}\right)$ signifikansi pada derajat kepercayaan $99 \%(\alpha=0,01)$

ns $=$ non signifikan

menunjukkan pengaruh secara signifikan ( $\mathrm{P}>0,05)$ (Tabel 6) dan Nagelkerke $R$ Square sebesar 0.842 menunjukkan bahwa keempat variabel bebas (umur, lahan, pendidikan dan pendapatan) mampu menjelaskan variasi keputusan petani untuk berbudidaya sertifikat prima 3 sebesar $84,2 \%$ sedangkan $15,8 \%$ dijelaskan oleh faktor lain di luar model

Tingkat pendidikan $\left(\mathrm{X}_{3}\right)$ dengan nilai odds ratiosebesar 72,44 menunjukkan nilai signifikansi. Artinya setiap peningkatan pendidikan petani sebesar satu tahun maka kecenderungan petani memutuskan untuk budidaya salak Nglumut bersertifikat 72,44 kali. Tingkat pendidikan petani baik formal maupun non formal akan mempengaruhi cara berfikir yang diterapkan pada usahanya yaitu dalam rasionalisasi usaha dan kemampuan memanfaatkan setiap kesempatan yang ada.Pendidikan, petani yang berpendidikan tinggi adalah relatif lebih cepat dalam melaksanakan adopsi inovasi.Begitu pula sebaliknya mereka yang berpendidikan rendah, mereka agak sulit untuk melaksanakan adopsi inovasi dengan cepat (Soekartawi, 1988). Mardikanto (1996) menerangkan pendidikan merupakan proses imbal balik dari setiap pribadi manusia dalam penyesuaian dirinya dengan alam, teman dan alam semesta.

Variabel pendapatan (X4) dengan nilai odds ratio sebesar 14,46 menunjukkan nilai signifikansi. Artinya setiap peningkatan pendapatan petani sebesar satu poin maka probabilitas petani memutuskan untuk budidaya salak Nglumut bersertifikat 14.46 kali. Beberapa penelitian menemukan ada pengaruh yang signifikan antara variabel pendidikan dan pendapatan terhadap tingkat adopsi. Soekartawi (1988) menjelaskan pendapatan petani bisa menjadi penyebab kemauan untuk melakukan percobaan atau perubahan dalam difusi inovasi pertanian yang cepat sesuai dengan kondisi pertanian yang dimiliki oleh petani.

Variabel X1 (umur) dan X2 (luas lahan) usaha tani memberikan pengaruh yang tidak nyata. Kusai (1997) yang menjelaskan bahwa variabel umur bukanlah variabel yang menentukan tingkat adopsi teknologi oleh petani ikan. Terkait dengan luas lahan, Saragih (2001) menyatakan bahwa ukuran luas lahan selalu berhubungan positif dengan tingkat adopsi petani. Semakin luas lahan petani semakin cepat mengadopsi karena adanya kemampuan ekonomi yang lebih baik. Rata-rata luas lahan petani bersertifikan dan tidak bersertifikat Prima 3 masing-masing seluas $0,48 \mathrm{Ha}$ dan $0,33 \mathrm{Ha}$. Luas lahan yang diusahakan relatif sempit seringkali menjadi kendala untuk mengusahakan secara lebih efisien. Menurut Suratiyah (2006), dipandang dari sudut efisiensi semakin luas lahan yang diusahakan maka semakin tinggi produksi dan pendapatan per kesatuan luasnya. Luas lahan akan menentukan skala usahanya yang pada akhirnya akan mempengaruhi efisiensi.

\section{Strategi Pengembangan Salak Nglumut}

Salak nglumut merupakan komoditas unggulan serta andalan di Kabupaten Magelang. Jenis buah ini merupakan buah asli Indonesia yang memiliki prospek cukup baik untuk dikembangkan sebagai komoditi ekspor. Keunggulan Salak Nglumut terletak pada rasa yang khas dimana tidak dimiliki 
oleh jenis salak lainnya yaitu rasa daging buah salak yang manis meskipun umurnya masih muda. Berikut merupakan sub sistem agribisnis Salak Nglumut di Kabupaten Magelang

Pengembangan agribisnis salak Nglumut di Kabupaten Magelang ditetapkan target sebagai berikut : (1) Produktivitas per rumpun tanaman produktif sebesar $15 \mathrm{~kg} / \mathrm{th}$, (2) Ukuran Besar Kelas A ( $8-12$ buah per kg) dicapai $60 \%$ produksi per rumpun, (3) Ukuran Sedang Kelas B (13 - 17 buah per kg) dicapai 30\% produksi per rumpun, (4) Ukuran Kecil Kelas C (18 - 22 buah per kg) dicapai 10 produksi per rumpun dan (5) Tingkat kemasakan buah minimal $70 \%$. Panen dilaksanakan tiga kali dalam setahun. Panen raya biasanya jatuh pada bulan DesemberJanuari, panen sedang pada bulan Mei-Juni sedangkan panen kecil pada bulan MaretApril. Pemanenan dilaksanakan oleh pemilik lahan dan atau tenaga kerja luar keluarga.

Analisis SWOT (Strenght, Weakness, Opportunity, threat) digunakan untuk merumuskan alternatif strategi pengembangan Salak Nglumut bersertifikat Prima 3 di Kabupaten Magelang. Faktor-faktor yang mempengaruhi pengembangan usaha diidentifikasi dengan menyusun matriks internal dan eksternal (Tabel 7).

Matriks eksternal digunakan untuk mengidentifikasi dan mengevaluasi kondisi eksternal perusahaan yang terdiri dari peluang (opportunity) dan ancaman (threat) yang dihadapi (Tabel 7). Berdasarkan hasil penilaian matrik IFAS (Internal Factor Analisis Summary) pada Tabel 7 menunjukkan angka total skor pada faktor kekuatan sebesar 1,88 dan skor pada kelemahan sebesar 1,25. Hal ini menunjukkan bahwa pengembangan agribisnis Salak Nglumut Kabupaten Magelang memiliki kekuatan yang lebih besar dibandingkan dengan kelemahannya dengan selisih sebesar 0,62 . Sementara untuk identifikasi faktor eksternal yang ditunjukan pada Tabel 8 diketahui bahwa skor peluang sebesar 2,20 dan skor pada ancaman sebesar 0,91 sehingga menunjukkan bahwa peluang pengembangan Salak Nglumut lebih besar dari ancaman dengan selisih 1,29.

Berdasarkan Tabel 7 dan 8 tersebut, selanjutnya diplotkan pada gambar/ilustrasi analisis diagram. Pada diagram analisis SWOT, sumbu $\mathrm{X}$ adalah selisih antara kekuatan dan kelemahan, sedangkan sumbu Y adalah selisih antara peluang dan ancaman. Selisih skor dari faktor kekuatan, kelemahan,

Tabel 7. Matriks IFAS (InternalFactor Analysis Summary)

\begin{tabular}{llcc}
\hline Faktor - faktor Strategi Internal & Bobot & Rating & Nilai \\
\hline $\begin{array}{l}\text { Kekuatan (strenght) } \\
\text { 1. Produk salak nglumut mempunyai keunggulan }\end{array}$ & 0,15 & 3,53 & 0,53 \\
$\quad$ karakteristik & 0,14 & 3,10 & 0,43 \\
2. Ketersediaan SDM besar & 0,14 & 3,33 & 0,47 \\
3. Pengalaman petani budidaya salak sudah & 0,14 & 3,20 & 0,45 \\
$\quad$ ditekuni cukup lama & 0,57 & & 1,88 \\
4. Sarana teknologi pasca panen (packing house) & & & \\
$\quad$ Total & & & \\
Kelemahan (weakness) & 0,11 & 3,07 & 0,34 \\
1. Luas lahan sempit & 0,11 & 3,10 & 0,34 \\
2. Belum menerapkan standar mutu produk & 0,11 & 2,83 & 0,31 \\
3. Belum memanfaatkan packing house secara & 0,10 & 2,63 & 0,26 \\
$\quad$ optimal & 0,43 & & 1,25 \\
4. Kelembagaan kelompok tani belum optimal & & \\
\hline$\quad$ Total & &
\end{tabular}


Tabel 8. Matriks EFAS (External Factor Analysis Summary)

\begin{tabular}{lccc}
\hline Faktor - faktor Strategi Eksternal & Bobot & Rating & Nilai \\
\hline $\begin{array}{l}\text { Peluang (Opportunity) } \\
\text { 1. Permintaan produk bersertifikat semakin tinggi }\end{array}$ & 0,15 & 3,57 & 0,54 \\
2. Dukungan pemerintah dengan fasilitasi sertifikasi & 0,14 & 3,50 & 0,49 \\
$\quad$ produk dan promosi & & & \\
3. Ketersediaan jaringan pemasaran & 0,13 & 3,40 & 0,44 \\
4. Akses informasi pasar mudah & 0,12 & 3,23 & 0,39 \\
5. Sarana Prasarana memadai & 0,12 & 2,87 & 0,34 \\
$\quad$ Total & 0,66 & & 2,20 \\
& & & \\
Ancaman (Threat) & & & \\
1. Adanya siklus bencana alam lima tahunan & 0,12 & 3,30 & 0,40 \\
$\quad$ (dampak gunung meletus) & & & \\
2. Pemalsuan produk bersertifikat & 0,11 & 2,47 & 0,27 \\
3. lahan ditanami komoditi lain & 0,11 & 2,23 & 0,25 \\
$\quad$ Total & 0,34 & & 0,91 \\
\hline
\end{tabular}

peluang dan ancaman, diperoleh koordinat $(0,62 ; 1,29)$ digunakan dalam penentuan posisi Salak Nglumut pada diagram SWOT seperti ditunjukkan pada Ilustrasi 1.

Menurut Rangkuti (2002), kuadran I pilihan strateginya adalah aggresive strategy atau strategi SO (strenghts-opportunities), kuadran II pilihan strateginya adalah diversification strategy atau strategi ST (strengths-threats), kuadran III pilihan strateginya adalah improvement strategy atau strategi WO (weaknesses-opportunities), dan kuadran IV pilihan strateginya adalah defense dan survival strategy atau strategi WT (weaknesses-threats). Berdasarkan hasil diagram Ilustrasi 1. dapat diketahui bahwa

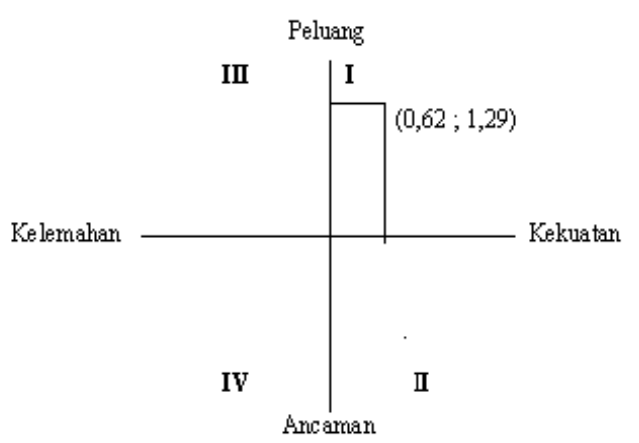

Ilustrasi 1.Diagram SWOT perusahaan berada dalam kuadran I. Strategi yang sebaiknya digunakan adalah strategi yang mendukung pertumbuhan agresif dengan memanfaatkan peluang yang ada diuraikan pada Tabel 9.

Berdasarkan analisis matrik SWOT pada Tabel 9 alternatif strategi yang digunakan yaitu strategi kekuatan dan peluang (strategi $\mathrm{S}-\mathrm{O}$ ). Strategi ini dibuat berdasarkan jalan pikiran perusahaan yaitu dengan menggunakan seluruh kekuatan untuk memanfaatkan peluang sebesar-besarnya (Rangkuti, 2002). Strategi S-O meliputi: Teknologi budidaya dan manajemen usaha diarahkan menggunakan pedoman budidaya yang baik (good Agricultural Practice) menuju sertifikasi produk prima, Penerapan standarisasi produk (penyeragaman mutu dan ukuran salak), penguatan pengembangan pasar, membuka jaringan pemasaran dan orientasi ekspor, pengembangan usaha dan peningkatan kapasitas produksi.

\section{KESIMPULAN}

Berdasarkan hasil penelitian dapat diambil kesimpulan bahwa hasil analisis regresi logistik menunjukan bahwa faktor pendidikan dan pendapatan petani memiliki pengaruh terhadap pengambilan keputusan 
Tabel 9. Formulasi Analisis Matrik SWOT

\begin{tabular}{|c|c|}
\hline $\begin{array}{r}\text { IFAS } \\
\text { (Internal Factor } \\
\text { Analisis Strategy) }\end{array}$ & $\begin{array}{l}\text { Kekuatan (Strenght) } \\
\text { 1. Produk salak nglumut mempunyai } \\
\text { keunggulan karakteristik } \\
\text { 2. Ketersediaan SDM besar } \\
\text { 3. Pengalaman petani budidaya salak sudah } \\
\text { ditekuni cukup lama } \\
\text { 4. Sarana teknologi pasca panen (packing } \\
\text { house) }\end{array}$ \\
\hline $\begin{array}{l}\text { Peluang (Opportunity) } \\
\text { 1. Permintaan produk bersertifikat } \\
\text { prima } 3 \text { semakin tinggi } \\
\text { 2. Dukungan pemerintah dengan } \\
\text { fasilitasi sertifikasi produk } \\
\text { 3. Ketersediaan jaringan pemasaran } \\
\text { 4. Akses informasi pasar mudah } \\
\text { 5. Sarana prasarana memadai }\end{array}$ & $\begin{array}{l}\text { Strategi S-O } \\
\text { 1.Teknologi budidaya dan manajemen usaha } \\
\text { diarahkan menggunakan pedoman budidaya } \\
\text { yang baik (Good Agricultural Practice) } \\
\text { menuju sertifikasi produk prima } \\
\text { 2. Penerapan standarisasi produk } \\
\text { (penyeragaman mutu dan ukuran salak) } \\
\text { 3. Penguatan pengembagan pasar, membuka } \\
\text { jaringan pemasaran dan orientasi ekspor } \\
\text { 4. Pengembangan usaha dan peningkatan } \\
\text { kapasitas produksi }\end{array}$ \\
\hline
\end{tabular}

petani dalam penerapan budidaya salak nglumut bersertifikat prima 3. Hasil analisis SWOT Matriks menunjukan bahwa posisi usaha agribisnis Salak Nglumut Bersertifikat Prima 3 di Kabupaten Magelang berada pada kuadranI. Strategi yang sebaiknya digunakan adalah strategi yang mendukung pertumbuhan agresif dengan memanfaatkan peluang (S-O) meliputi strategi : (a) Teknologi budidaya dan manajemen usaha diarahkan menggunakan pedoman budidaya yang baik (Good Agricultural Practice) menuju sertifikasi produk prima, (b) Penerapan standarisasi produk (penyeragaman mutu dan ukuran salak), (c) Penguatan pengembagan pasar, membuka jaringan pemasaran dan orientasi ekspordan (d) Pengembangan usaha dan peningkatan kapasitas produksi

\section{DAFTAR PUSTAKA}

BPS. 2013. Kabupaten Magelang Dalam Angka Tahun 2013, Badan Pusat Statistik.Magelang

Dinas Pertanian Tanaman Pangan dan Hortikultura.2013, Standar Operasional Prosedur Salak Nglumut. Semarang
Kusai. 1997. Tingkat Adopsi Petani Ikan Terhadap Teknologi Budidaya Ikan Dalam Keramba Terapung (Kasus di Kecamatan Bangkinang Barat Kabupaten Kampar Propinsi Riau). Jurnal Penelitian Universitas Riau, 1 (1) : 76-80.

Mardikanto, T. 1996. Penyuluhan Pembangunan Pertanian. Sebelas Maret. University Press. Surakarta.

Rangkuti, F. 2002. Analisis SWOT Teknik Membedah Kasus Bisnis. Gramedia Pustaka Utama, Jakarta.

Saefuddin, A., K.A. Notodipuro, A. Alamudi dan K. Sadik. 2009. Statistika Dasar. Gramedia. Jakarta.

Said, M. dan Intan. 2004. Manajemen Agribisnis. Ghalia Indonesia. Jakarta.

Saragih.(2001). Penyuluhan, Petunjuk Bagi Penyuluh Pertanian. Erlangga: Jakarta.

Sugino, T. and H. Mayrowani. 2010. Perspective of Organik Vegetable Production in Indonesia under the Regional Economic Integration Case study in West Java , Sutheast Agriculture-Opportunities and Challenges under Economic Integration. JIRCAS Working Report. 
Soekartawi. 1988. Prinsip Dasar Komunikasi

Pertanian. Universitas Indonesia Jakarta
Suratiyah, K. 2006. Ilmu Usahatani. Penebar Swadaya. Jakarta 